\title{
AUMENTO DA PRODUTIVIDADE DAS PÁS CARREGADEIRAS CAT 990 NO CARREGAMENTO DE VAGÕES NO PÁTIO DE PRODUTOS NA MINA DE ALEGRIA*
}

Admilson José Borges ${ }^{1}$

\section{Resumo}

Substituir todo o texto de orientação deste Template pelo conteúdo de seu trabalho. Inserir o texto com no máximo 1.500 caracteres (200 palavras), sem uso de parágrafos. Deve conter, de maneira concisa, o objetivo, a metodologia, os resultados e as conclusões do trabalhoO presente trabalho buscou identificar as principais oportunidades de melhoria na operação de carregamento de vagões no pátio de produtos na mina de Alegria em Mariana, com o propósito de aperfeiçoar, estabilizar e padronizar o processo, consequentemente aumentando-se a produtividade das pás carregadeiras CAT 990, minimizando o tempo de estadia do trem no pátio de produtos e o custo da operação. A elaboração do estudo no setor de expedição de produtos foi baseada em decisões orientadas pela ferramenta de melhoria contínua Seis Sigma e em análises de fatos e dados. Os resultados foram validados através da superação da meta estabelecida para o projeto, onde o objetivo inicial foi aumentar em $8,1 \%$ a produtividade do equipamento em relação ao valor atual, porém conseguiu-se atingir o valor de $23,5 \%$ com um ganho anual de $R \$ 1,34$ milhões.

Palavras-chave: Produtividade; Carregamento de vagões; Tempo de estadia; Pátio de produtos.

\section{INCREASED PRODUCTIVITY OF WHEEL LOADERS CAT990 ON LOADING WAGONS IN THE PATIO OF PRODUCTS IN ALEGRIA MINE}

\begin{abstract}
The present work aimed to identify the main opportunities for improvement in the loading of wagons in the yard of products in the Alegria mine, with the purpose of improving, stabilizing and standardizing the process, consequently increasing the productivity of the CAT 990 wheel loaders, minimizing the time of stay of the train in the patio of products and consequently the cost of this operation. The preparation of the study in the field of shipment of products was based on decisions guided by the Six Sigma continuous improvement tool and in facts and data analyzes. The results were validated by overcoming the project's target, where the initial objective was to increase equipment productivity by $8.1 \%$ in relation to the current value, but was able to reach a value of $23.5 \%$ with a gain of $R \$ 1.4$ million
\end{abstract}

Keywords: Productivity; Loading wagons; Length of stay; Patio products

1 Admilson José Borges, Engenheiro Sênior, Infraestrutura de Mina, Vale SA, Mariana, Minas Gerais, Brasil. 


\section{INTRODUÇÃO}

A expedição no pátio da mina de Alegria é totalmente realizada por pás carregadeiras, o que a difere dos outros sites da Vale que são realizados através de silos. As pilhas no pátio de produtos são formadas por caminhões e estas são retomadas pelas pás carregadeiras a fim de carregar os vagões. A operação é realizada por cinco máquinas de carga de médio porte, sendo todas do modelo CAT 990, pois há um tempo pré-determinado para carregar um lote de trem de 84 vagões, não podendo assim, extrapolar o limite de permanecia do ativo no pátio. Caso ultrapasse o tempo determinado para carregar a composição, há risco de não cumprir o programa de lotes estabelecidos para o dia, prejudicando assim toda cadeia produtiva. A figura 1 representa o layout do pátio de expedição de produtos na mina de Alegria, onde cada letra representa um estoque e cada cor um tipo de produto.

Figura 1 - Layout do pátio de expedição de produtos da mina de Alegria, as áreas de estocagem e os respectivos produtos estocados

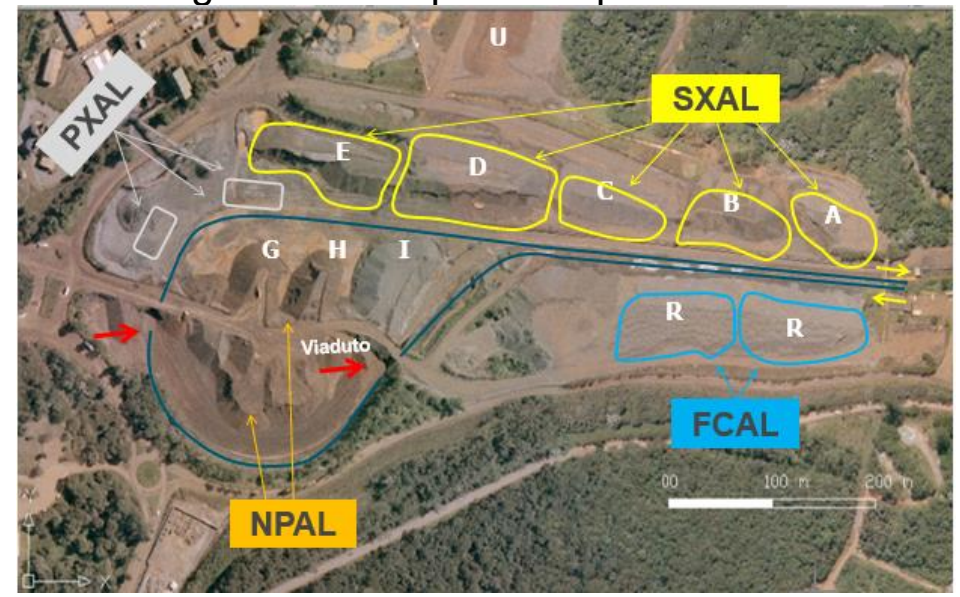

Fonte: Arquivo interno Vale S.A.

O processo de carregamento influencia diretamente no ritmo da expedição, sendo desta forma, crítico para a cadeia produtiva a qual opera 24 horas por dia.

Com o aumento da produtividade das pás carregadeiras, consequentemente o custo operacional e o tempo de estadia do trem no ponto de carga serão reduzidos, aumentando por consequência, a quantidade de lotes expedidos no pátio.

\subsection{Processo de carregamento de Vagões}

A operação na expedição é iniciada quando o trem chega ao pátio de produtos, e o mesmo é posicionado ao lado da pilha a ser carregada. Logo após, se inicia a operação de carregamento dos vagões com as pás. Após o carregamento, os produtos são aspergidos com uma solução (água + polímero biodegradável) para evitar que o minério se disperse e gere impactos sociais com as comunidades no entorno da malha ferroviária. Para finalizar o processo, os vagões são pesados para controlar a massa da carga. A figura 2 mostra a operação de carregamento de produtos nos vagões pelo meio de pás carregadeiras. 
Figura 2 - Operação de carregamento de vagões

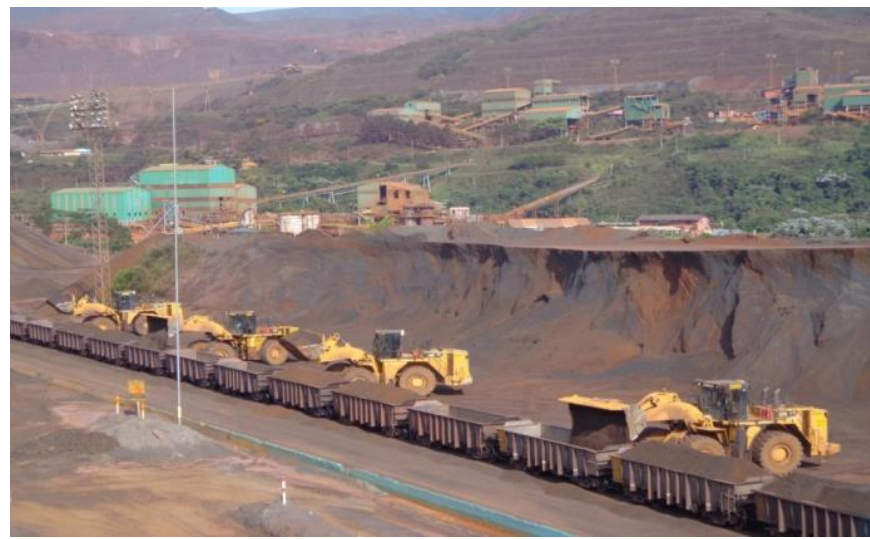

Fonte: Arquivo interno Vale Figura

Para o cálculo do indicador principal do projeto foram consideradas a massa carregada em tonelada nos vagões e as horas trabalhadas dos equipamentos na operação.

A produtividade é calculada a partir da equação 1:

Onde:

$$
P=\frac{M(t)}{H t(h)}
$$

P: Produtividade do carregamento (toneladas por hora)

M: Massa carregada nos vagões (toneladas)

HT: Hora trabalhada do equipamento na operação (horas)

\section{MATERIAIS E MÉTODOS}

O método de melhoria contínua empregado para auxiliar na resolução do problema foi o Seis Sigma com um auxílio da ferramenta PDCA, a qual foi possível obter informações importantes que contribuíram para o alcance do objetivo do projeto.

\subsection{Identificação do problema}

\subsubsection{Definição da meta}

Ao analisar os dados, foi possível definir a meta geral para que a produtividade que estava sendo realizada se aproximasse da idealizada. Para definição da meta, a equipe utilizou a base de dados do período de junho/2014 a dezembro/2014 e através do método dos quartis, chegou-se ao valor de referência. Como o comportamento do indicador é quanto maior, melhor, adotou-se o terceiro quartil como o valor da meta, sendo que este representa $75 \%$ das amostras que tem 0 valor de $708,1 \mathrm{t} / \mathrm{h}$. 
Figura 3 - Cálculo da meta através do método dos quartis

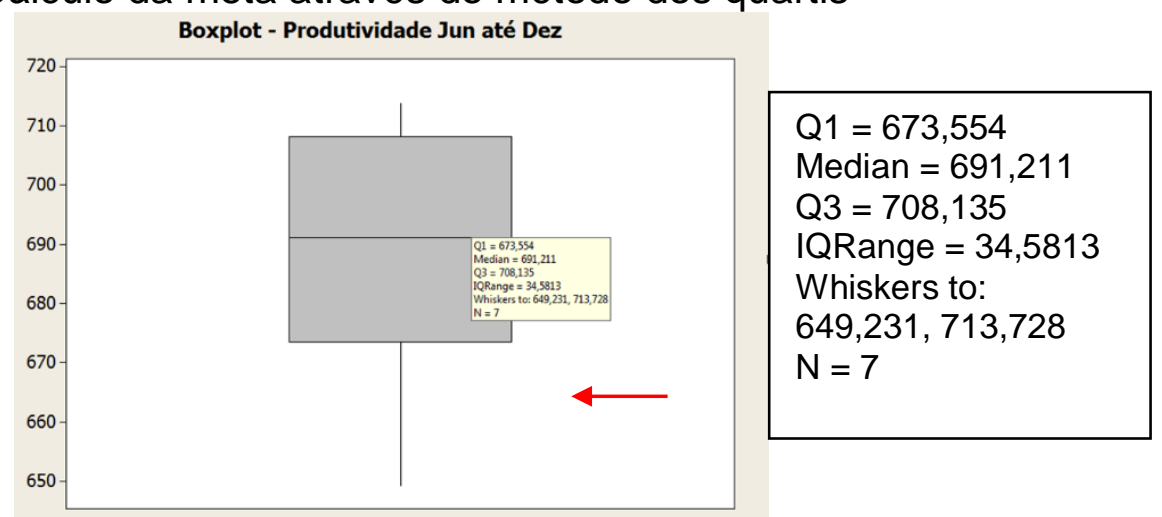

Fonte: Adaptado Minitab

\subsection{Análise do Fenômeno}

\subsubsection{Estratificação do indicador}

A estratificação do indicador facilita o andamento do projeto, pois ela auxilia as buscas das possíveis causas que influenciam direta e indiretamente 0 comportamento da produtividade. $O$ indicador foi estratificado da seguinte forma:

Produtividade $\rightarrow$ Turno $\rightarrow$ Turma $\rightarrow$ Área $\rightarrow$ Produto.

Para conhecer melhor o comportamento dos dados, foram realizados para cada produto, estatísticas descritivas e vários tipos de gráficos com o auxílio do software Minitab. Os gráficos são do tipo histograma, teste de normalidade, carta de controle e análise de desempenho. E importante salientar que a análise foi baseada nos últimos 3 meses do período estudado.

Figura 4 - Estatística descritiva do produto NPAL

\begin{tabular}{|c|c|c|r|r|r|r|r|c|}
\hline $\begin{array}{c}\text { Estatísticas } \\
\text { Descritivas }\end{array}$ & $\mathrm{N}$ & Média & $\begin{array}{c}\text { Desvio } \\
\text { Padrão }\end{array}$ & Mínimo & $\begin{array}{c}10 \\
\text { Quartil }\end{array}$ & Mediana & $\begin{array}{c}\text { 30 } \\
\text { Quartil }\end{array}$ & Máximo \\
\hline NPAL & 55 & 592,00 & 85,30 & 390,00 & 546,00 & 593,50 & 650,00 & 758,30 \\
\hline
\end{tabular}

Fonte: Adaptado Minitab

Ao analisar os histogramas de cada produto, observa-se que a distribuição dos dados é normal, pois o valor da frequência máxima se aproxima do valor da média e da mediana.

Figura 4 - Histograma do produto NPAL

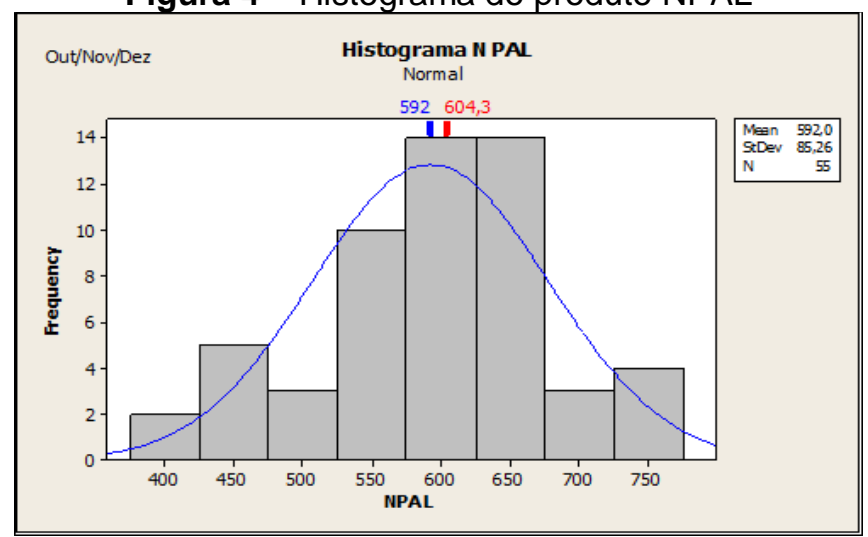


Fonte: Adaptado Minitab

Utilizando-se o teste de normalidade, percebe-se que os dados seguem uma distribuição normal.

Figura 5 - Teste de normalidade

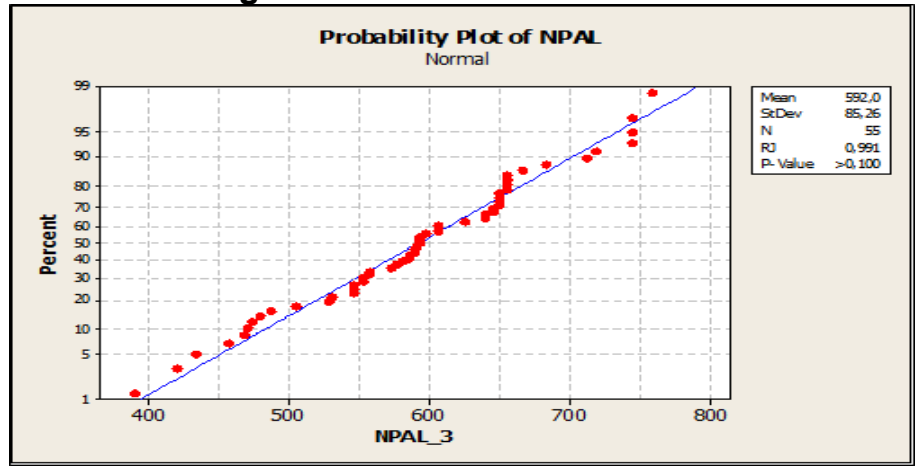

Fonte: Adaptado Minitab

A carta de controle é utilizada de uma maneira geral para analisar a estabilidade do processo, de acordo com a presença de causas comuns, quando os pontos são distribuídos dentro dos limites, e causas especiais, quando há pontos fora dos limites.

Figura 6 - Carta de controle do produto NPAL

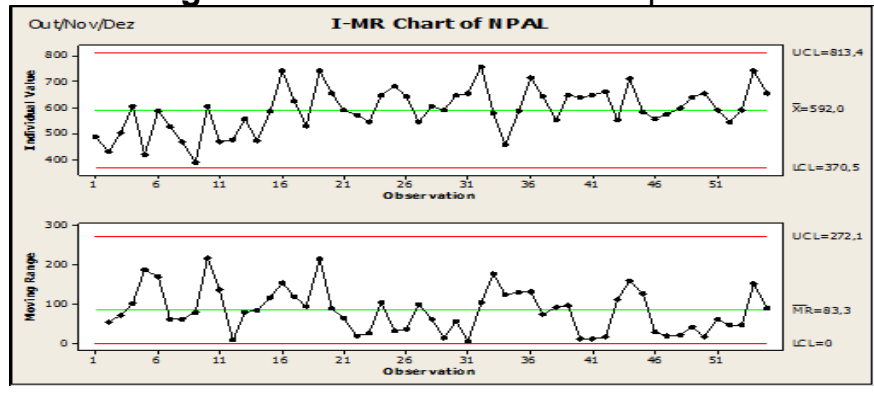

Fonte: Adaptado Minitab

A análise de desempenho verifica se o processo atende ou não a especificação de acordo com o Ppk - (causas comuns e especiais do processo) e mostra o percentual dos dados que estão fora da faixa de especificação. Em todos os produtos, tem-se que os processos não atendem às especificações e que a porcentagem em que a produtividade ficou abaixo do valor especificado foi alta.

Figura 7 - Análise de desempenho do produto NPAL 


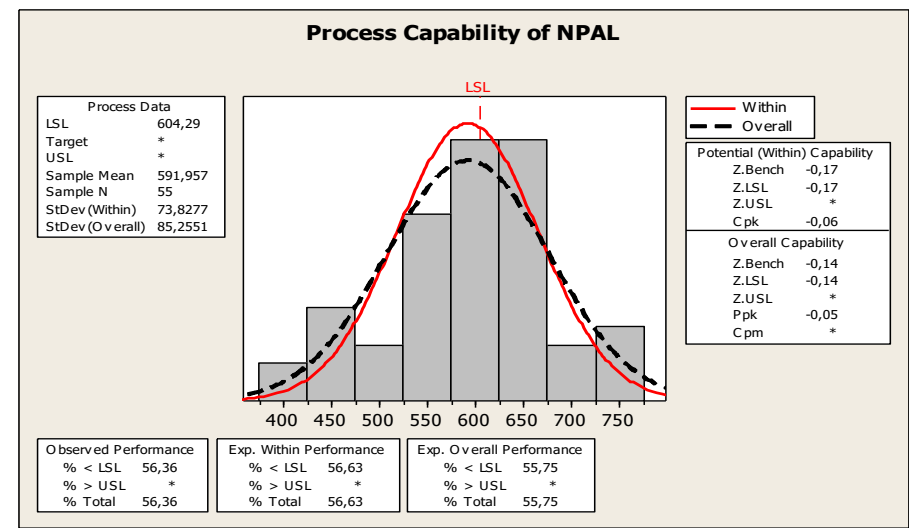

Fonte: Adaptado Minitab

\subsection{Metas específicas}

Para o alcance da meta geral, foi necessário estipular metas específicas para cada produto. Foi feita a média ponderada entre a porcentagem da massa orçada para carregar cada produto e a meta específica calculada para cada um deles.

\subsection{Análise do Processo}

\subsubsection{Levantamento das causas do problema}

Através do brainstorming realizado com todos os operadores envolvidos no projeto, puderam-se levantar todas as causas presentes na atividade. Foram levantadas 40 possíveis causas e essas foram analisadas através da matriz de priorização dos focos sendo priorizadas 6 causas com os critérios de impacto, custo, complexidade e prazo como se pode observar na tabela 1.

Tabela 1 - Priorização das causas

\begin{tabular}{|c|c|}
\hline \multicolumn{2}{|r|}{ CAUSAS PRIORIZADAS } \\
\hline 1 & $\begin{array}{l}\text { Velocidade limitada na aspersão dos produtos: SXAL 3Km/h e PXAL } \\
\qquad 1,5 \mathrm{Km} / \mathrm{h} \text {. }\end{array}$ \\
\hline 2 & Alto tempo de manobra do trem durante o carregamento de vagões. \\
\hline 3 & $\begin{array}{l}\text { Efetivo da ferrovia disponível para a execução da atividade menor do } \\
\text { que o necessário. }\end{array}$ \\
\hline 4 & $\begin{array}{c}\text { Alto tempo de ciclo das Pás carregadeiras CAT } 990 \text { durante a } \\
\text { operação de carregamento dos vagões }\end{array}$ \\
\hline 5 & Falhas na planta de aspersão. \\
\hline 6 & $\begin{array}{l}\text { Padrão/sequência (Falta de padronização entre os operadores) de } \\
\text { carga dos vagões durante carregamento. }\end{array}$ \\
\hline
\end{tabular}

Fonte: Arquivo interno Vale

\subsection{Comprovação das causas priorizadas}

As causas priorizadas foram comprovadas através do software Minitab, análises estatísticas dos dados, por levantamentos topográficos e por imagens. Nessa comprovação, ficou muito claro que cada causa influencia diretamente no comportamento do indicador de produtividade.

\subsubsection{Velocidade limitada na aspersão dos produtos}


Figura 8 - Coeficiente de Person - correlação entre produtividade $x$ velocidade do trem durante a aspersão do produto

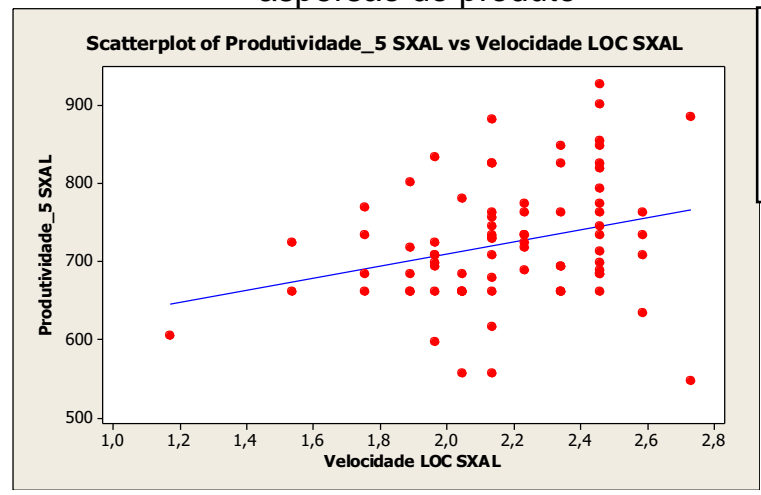

Coeficiente de Pearson $=0,285$

P-value $=0,011$

Fonte: Adaptado Minitab

\subsubsection{Alto tempo de manobra durante o carregamento de vagões}

Figura 9 - Gráfico de contorno

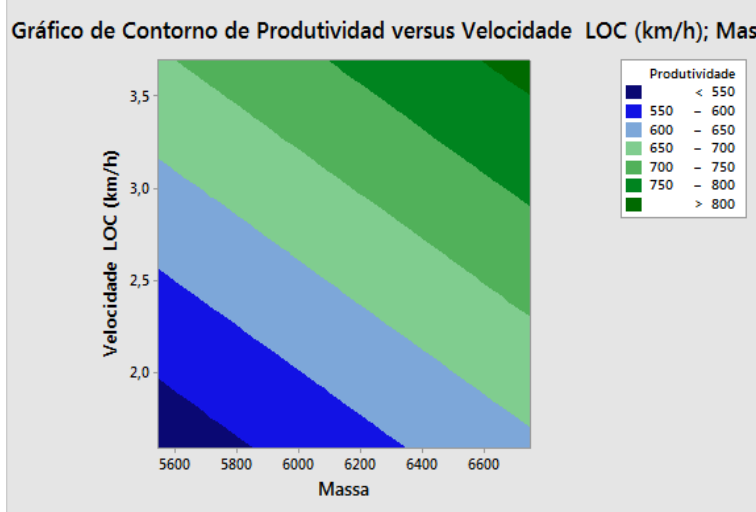

Fonte: Adaptado Minitab

\subsubsection{Falta de padronização entre os operadores na carga de vagões durante o carregamento}
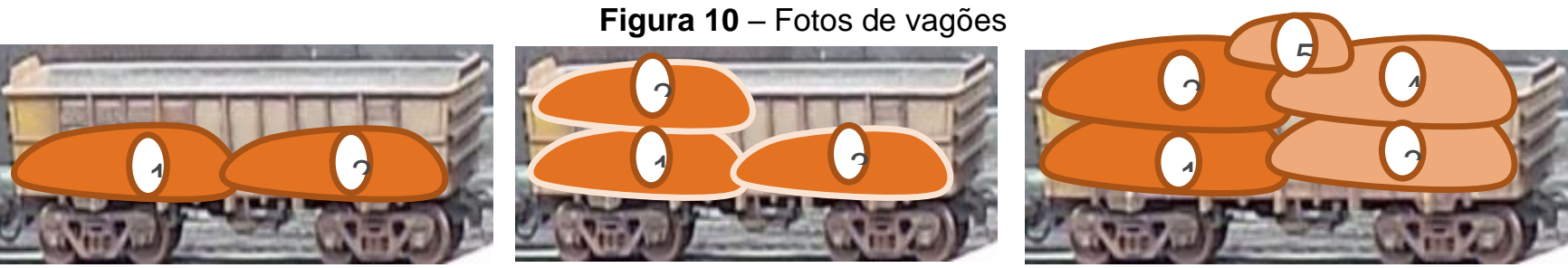

\subsection{Estabelecimento do Plano de ação}

Fonte: Arquivo interno Vale

Após as causas serem comprovadas, elaborou-se um plano com 26 ações para as áreas envolvidas no processo com o objetivo de eliminar os desvios.

\subsubsection{Implementação do plano de ação:}

\subsubsection{Treinamento de "Alta Concordância"}

Ministrou-se para os operadores e auxiliares um treinamento, no qual puderam vivenciar, através de discussões em grupo e dinâmicas, um ambiente onde 
enxergaram desperdícios e condições normais e anormais, analisando oportunidades e propondo melhorias do processo em grupo.

Figura 11 - Treinamento com operadores
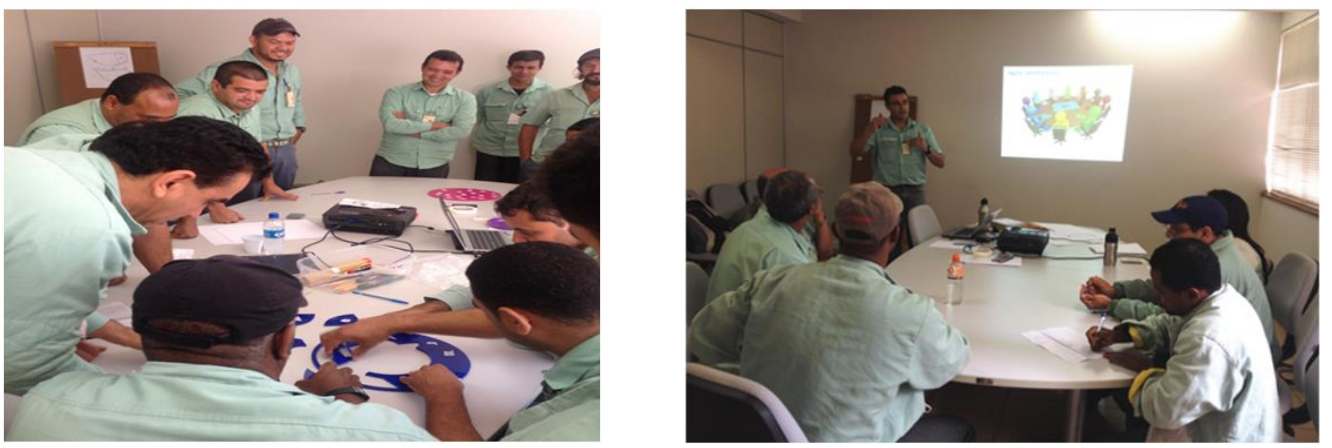

Fonte: Arquivo interno Vale

\subsubsection{Eliminação dos pontos de restrição}

Todos os pontos ou barreiras que impediam ou dificultavam as manobras e a operação das pás carregadeiras foram removidas.

Figura 12 - Equipamentos auxiliando a remoção dos pontos de restrição
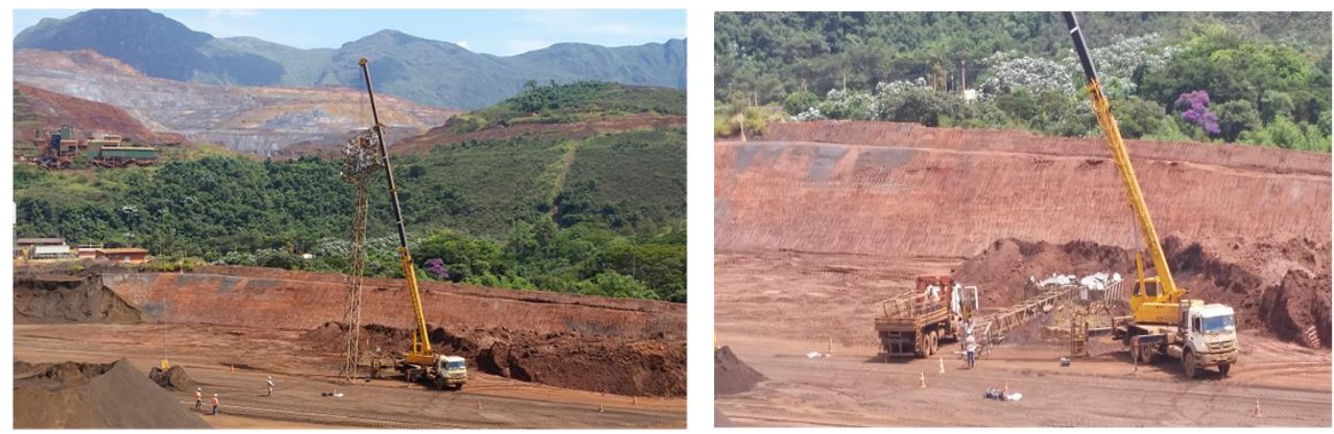

Fonte: Arquivo interno Vale

\subsubsection{Adequações na planta de aspersão}

O aumento da vazão da planta de aspersão foi feito através do trabalho de CCQ na gerência, o que possibilitou o aumento da velocidade do trem durante a aspersão de $1,5 \mathrm{~km} / \mathrm{h}$ para $3 \mathrm{~km} / \mathrm{h}$. A figura 13 mostra a planta de aspersão em seu pleno funcionamento.

Figura 13 - Planta de aspersão do pátio de expedição da mina de Alegria

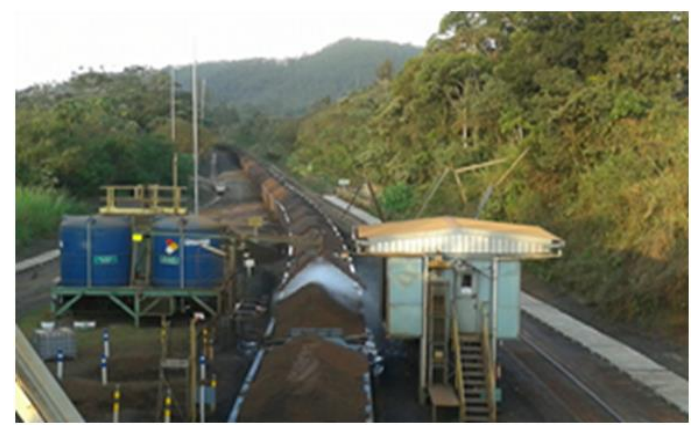

Fonte: Arquivo interno Vale

\subsubsection{Adequações nas áreas de estocagem dos produtos}


A figura 14 quando comparada com a figura 15, mostra a redução da quantidade de pilhas no pátio de produtos, com isso, obteve-se ganhos tangíveis como a redução de manobras do trem e maior velocidade do mesmo durante sua operação.

Figura 14 - Pátio de produtos antes do projeto



Fonte: Arquivo interno Vale

Figura 15 - Pátio de produtos depois do projeto

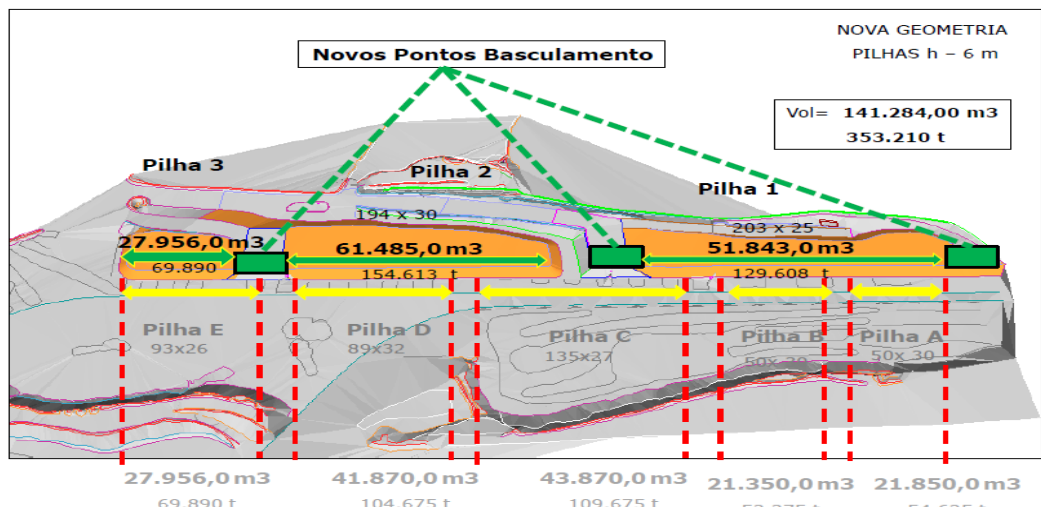

Fonte: Arquivo interno Vale

\subsubsection{Padronização da atividade}

Figura 16: Procedimento de carga

3o modelo de carregamento

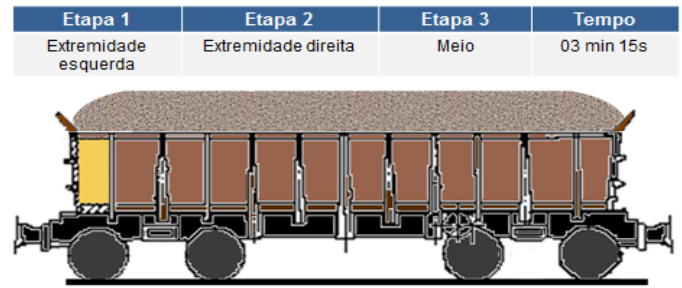

Fonte: Arquivo interno Vale

\subsubsection{Sinalização do ponto de carga e treinamento da equipe de operação ferroviária}

Toda a pera ferroviária foi sinalizada para orientar o deslocamento do trem dentro do ponto de carga.

Para uma melhor confiabilidade e melhor desempenho do projeto, todos os envolvidos na atividade foram treinados, incluindo os maquinistas sobre responsabilidade da gerencia de operações ferroviárias. 
Figura 17 - Sinalização da pera ferroviária

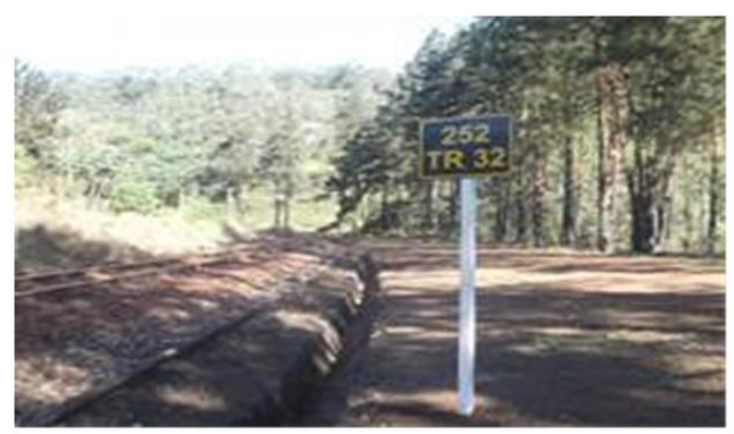

Fonte: Arquivo interno Vale

Figura 18 - Locomotiva Vale que leva as cargas nos vagões da mina de Alegria até o porto de Vitória - ES

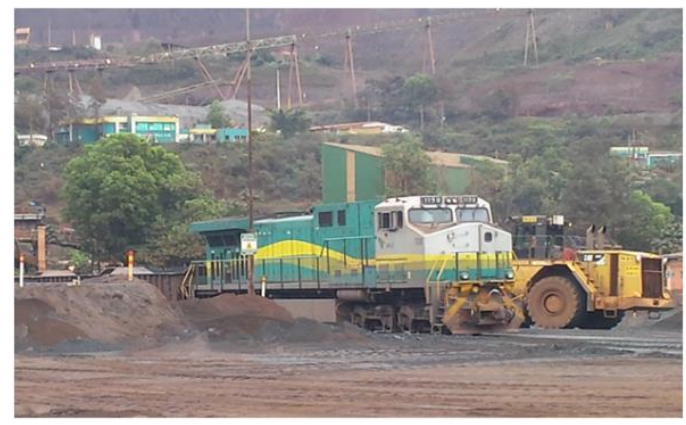

Fonte: Arquivo interno Vale

\section{RESULTADOS E DISCUSSÃO}

\subsection{Global}

Após todas as ações serem implementadas, a meta geral do projeto foi superada fazendo com que o indicador produtividade obtivesse um valor bem acima do esperado, como se pode notar na figura 19.

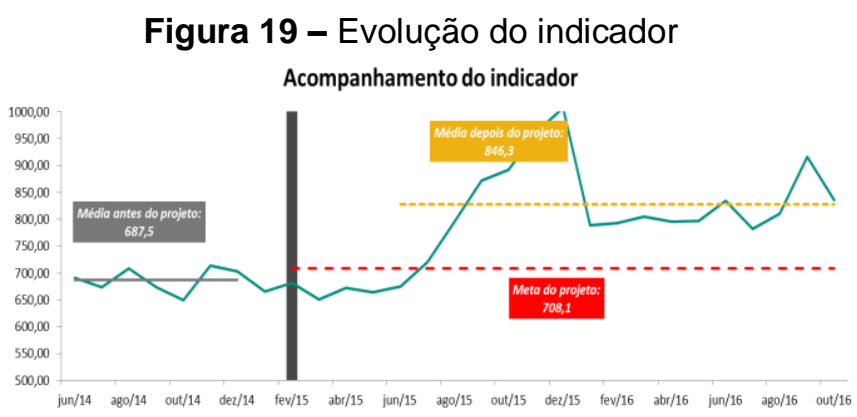

\subsection{Atendimento}

Fonte: Arquivo interno Vale

Figura 20 - Comparativo de capacidade mostrando a redução de resultados fora de especificação. 


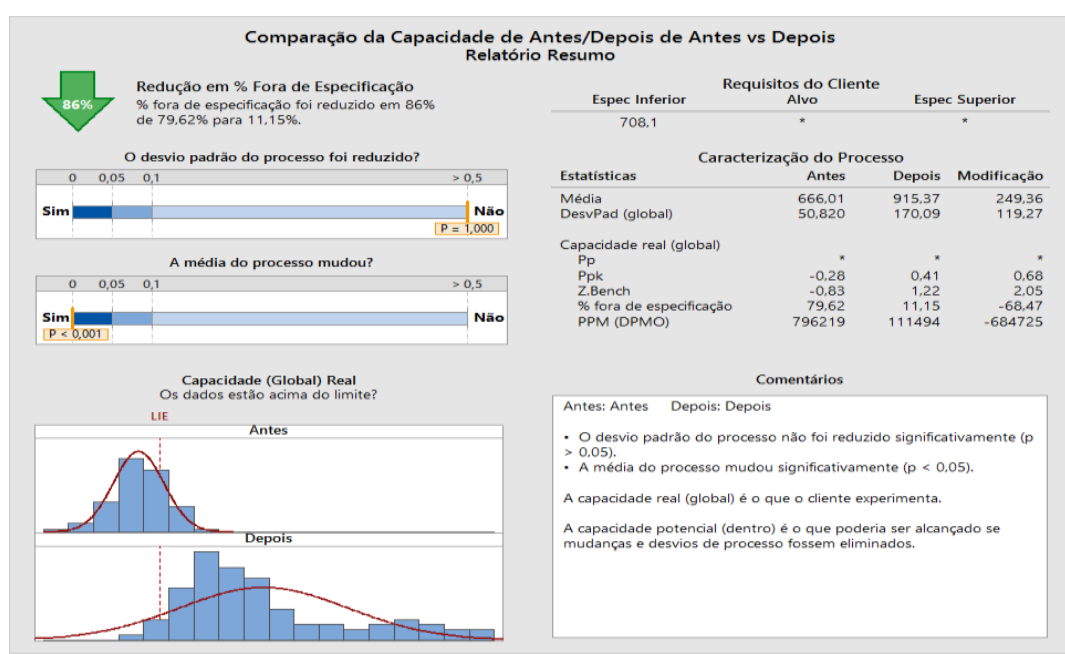

Fonte: Adaptado Minitab

\subsection{Ganhos quantitativos do projeto}

Figura 21: Redução de $25,3 \%$ no tempo de carregamento Tempo de Carregamento

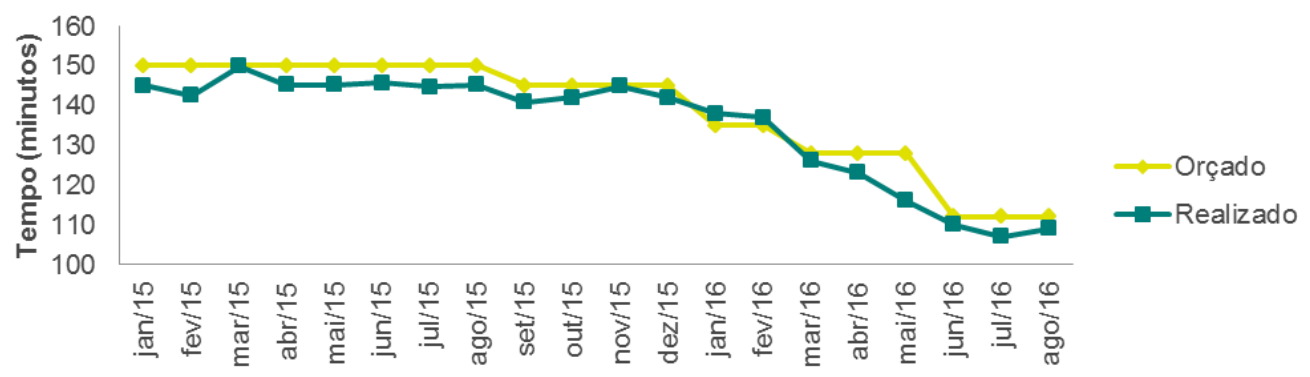

Fonte: Arquivo Vale

Figura 22: Redução de 39,5\% no tempo de estadia do trem Tempo de Estadia

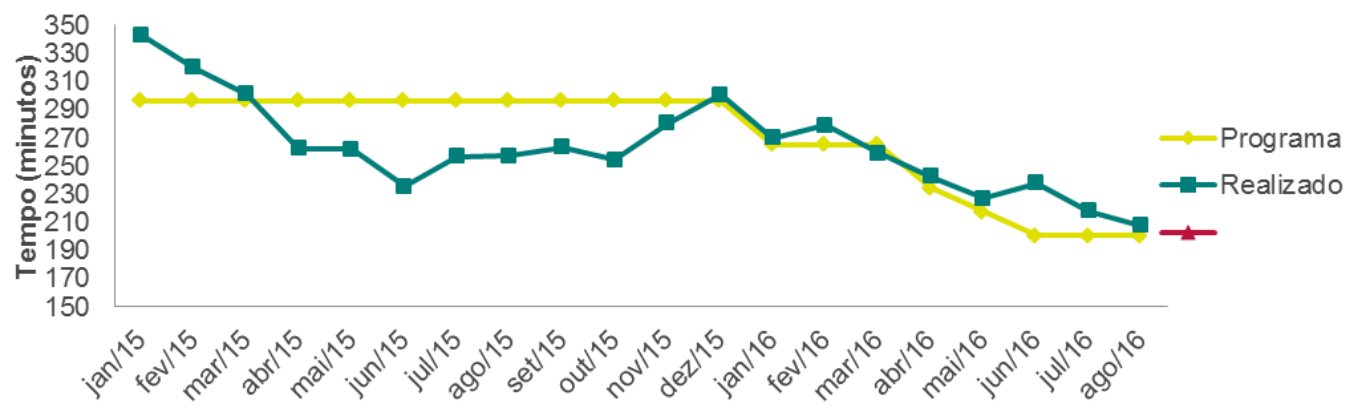

Fonte: Arquivo Vale

Figura 23: Aumento de volume de capacidade expedida (antes do projeto: 7 lotes diários; depois 11 lotes) 


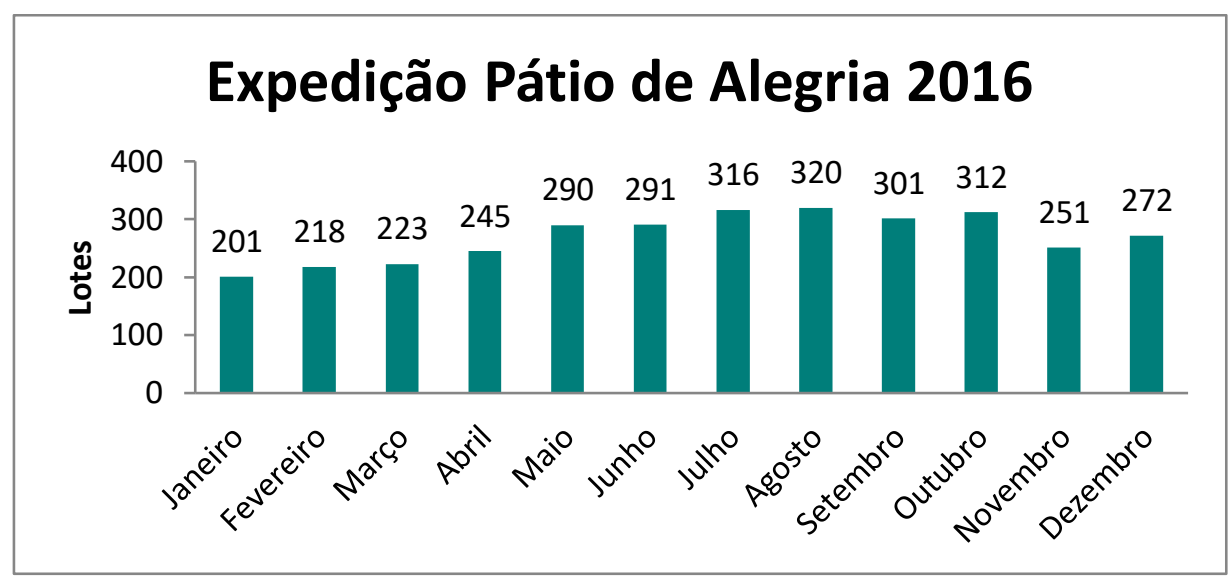

Fonte: Arquivo Vale

\section{CONCLUSÃo}

Com a finalização do projeto, além do ganho com o aumento da produtividade das pás carregadeiras, houve também ganhos em relação ao tempo de carregamento, tempo de estadia e o número de lotes. O tempo de carregamento sofreu uma redução de $25,3 \%$, já o tempo de estadia reduziu $39,5 \%$ e o número de lotes na expedição diária do pátio aumentou de 7 , para 11 lotes. Ressalta-se também 0 ganho potencial de aproximadamente $R \$ 1,34$ milhão, durante o período, o que contribui significativamente com a política de redução de custo da empresa. Além de tudo, este projeto pode ser aplicável em qualquer processo de mineração que utiliza carregamento de vagões com pá carregadeira.

\section{Agradecimentos}

Agradeço o apoio de toda equipe de Infraestrutura de Mina: supervisores, operadores, auxiliares de produção e instrutores de equipamentos que dentro de sua área de conhecimento contribuíram para o desenvolvimento deste estudo. Ao Juliano Reis, que nos apoiou incondicionalmente, conduzindo-nos para um resultado consistente e a equipe Ferroviária (Ricie Oliveira, Alexandre Viegas, Elísio Souza) que sempre estiveram disponíveis e se propuseram a realizar as mudanças necessárias para melhoria do processo e do ambiente de trabalho.

\section{REFERÊNCIAS}

1 Campos, V. F. Qualidade Gerenciamento da Rotina do Trabalho do Dia a Dia, $7^{a}$ Edição. Belo Horizonte: Editora de Desenvolvimento Gerencial; 2001.

2 Werkema, M. C. C. Criando a Cultura Seis Sigma. Nova Lima: Werkema Editora; 2004.

3 Werkema, M. C. C. Ferramentas Estatísticas Básicas para o Gerenciamento de Processos. Belo Horizonte: Fundação Christiano Ottoni, Escola de Engenharia UFMG; 1995 


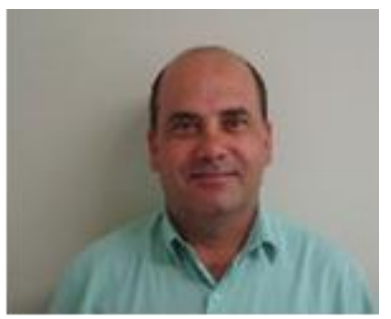

Admilson Borges. Engenheiro Sênior, graduado em Engenharia de Produção pela Universidade Presidente Antonio Carlos, formação de Green belt. Experiência de 10 anos em liderança na operação de Mina na Vale. Atualmente cursando Especialização Lato Sensu em Lavra de Minas a Céu Aberto pelo ITV (Instituto Tecnológico Vale em Ouro Preto,MG) 